Res Pública Revista de Historia de las Ideas Políticas

ISSN: 1131-558X

http://dx.doi.org/10.5209/rpub.71246

\title{
Café sin leche, Escuela sin concepto: rasgos, operaciones y lecturas en la Escuela eslovena
}

\author{
Carlos Gómez Camarena ${ }^{1}$ y Sergio Aguilar Alcalá
}

Recibido: 31 de agosto de 2020 / Aceptado: 18 de septiembre de 2020

Resumen. El siguiente artículo presenta un panorama más amplio de la filosofía de Slavoj Žižek, mostrando que es parte de un grupo más amplio que denominamos "Escuela eslovena". Es así que el artículo está compuesto por dos partes. La primera dedicada a mostrar el contexto histórico de emergencia de la Escuela eslovena. La segunda parte sostiene dos tesis: 1) hay una Escuela eslovena como sujeto impersonal, que implica que leer a uno de sus miembros hace más comprensible a otro; y, 2) a pesar de que no encontramos conceptos propios de esta Escuela, es posible encontrar rasgos, operaciones y lecturas en común entre ellos.

Palabras clave: Slavoj Žižek; Escuela eslovena; psicoanálisis; idealismo alemán; Lacan.

\section{[en] Coffee without Milk, School without Concept: Traits, Operations and Readings on the Slovenian School}

\begin{abstract}
The following paper presents a broader picture of Slavoj Žižek's philosophy, showing that his philosophy is part of a wider group that we call "Slovenian School". This article has two parts. The first part is devoted to the historical context and the origins of the Slovenian School. The second part sustains two thesis: 1) there is a Slovenian School as impersonal subject, which implies that reading one of their authors makes another author more comprehensible; and, 2) in spite of the absence of concepts in this School, it is possible to find original traits, operations and readings in common among their members.
\end{abstract}

Keywords: Slavoj Žižek; Slovenian School; Psychoanalysis; German Idealism; Lacan.

Sumario. 1. Una Escuela eslovena: breve contexto e historia. 2. Hay una Escuela eslovena de filosofía. 3. Rasgos, operaciones y lecturas. 3.1. Rasgos. 3.2. Operaciones. 3.3. Lecturas. 4. Conclusión. Bibliografía

Cómo citar: Gómez Camarena, C.; Aguilar Alcalá, S. (2020). Café sin leche, Escuela sin concepto: rasgos, operaciones y lecturas en la Escuela eslovena. Res Pública. Revista de Historia de las Ideas Políticas, 23(3), 305-319.

A partir de 1989, la filosofía no volvió a ser la misma. Ese año, a manera de intervención sobre la filosofía, fue publicado El sublime objeto de la ideología ${ }^{3}$, lo que cambió las coordenadas del horizonte filosófico ${ }^{4}$, al menos sobre los debates de finales del siglo XX. Su autor, el ahora conocido mundialmente Slavoj Žižek, leía por vez primera un variado corpus filosófico a través de la lente del psicoanálisis lacaniano, brincando de un tema a otro y trayendo a la mesa de discusión la cultura pop. Se trataba de una nueva concepción de la ideología que retomaba las teorías de Marx y Althusser, leídos ahora a través de los complejos aparatos de escritura lacanianos tales como el objeto $a$, el grafo del deseo, los nudos borromeos o las fórmulas de la sexuación. Si bien Althusser o Ernesto Laclau ya habían construido sus propios ensambles de lecturas contraintuitivas sobre una amplia variedad de filósofos (de Platón a Heidegger pasando por Descartes, Kripke o Kant), no era parte de su construcción teórica de mayor amplitud. Además con un extra que ya señalamos: el complejísimo entramado filosófico y la árida conceptualización lacaniana son ejemplificadas a través de chistes, películas y otros elementos

\footnotetext{
Universidad Iberoamericana Ciudad de México carlos.gomez@ibero.mx

2 Universidad Iberoamericana Ciudad de México

Andrew Mellon Grant post-MA fellowship,

"Extimacies: Critical Theory from the Global South"

sergio.aguilaralcala@gmail.com

S. Žižek, El sublime objeto de la ideología, México, Siglo XXI, 1992.

4 Por ejemplo, en el libro La filosofía del siglo $X X$, se hace un recorrido de la filosofía del siglo pasado mediante una lista de los 31 libros más importantes que fueron publicados: El sublime objeto de la ideología forma parte de esa selección. L. Guerrero y A. Cavallazzi, La filosofía del siglo XX: un mapa bibliográfico, México, Universidad Iberoamericana, 2010.
} 
de la cultura pop. ¿En qué radica la novedad filosófica de este libro? ¿Qué es lo que pudo ser pensado por vez primera y que eleva este ensayo a la dignidad de intervención en la filosofía?

De hecho, El sublime objeto de la ideología (SOI en adelante) es en realidad una reescritura de la segunda tesis de doctorado del filósofo esloveno, cuyo título fue El más sublime de los histéricos, tesis de doctorado en psicoanálisis en la Universidad Paris 8 Vincennes bajo la dirección de Jacques-Alain Miller, quien también dirigía la Escuela Doctoral de este posgrado. Defendida en 1985 y publicada tan sólo tres años después en la editorial francesa de psicoanálisis Point hors ligne $e^{5}$ la tesis sostiene una lectura al estilo "Kant con Sade". En efecto, en la primera parte del libro ensaya una lectura de Hegel mediante Lacan que a su vez es una lectura de Lacan a través de Hegel. "X con Y" y luego "Y con $X$ " se trata de una matriz esencial de doble vectorización que es repetida bajo otros aspectos en ¡Goza tu síntoma! $!^{6}$ o en Todo lo que usted siempre quiso saber sobre Lacan y nunca se atrevió a preguntarle a Hitch$c o c k^{7}$ : Lacan con la cultura pop (y viceversa) en el primero, Hitchcock con Lacan (y al revés) en el último. Hegel con Lacan, eso responde a nuestra pregunta. Lo inédito de $S O I$ es justamente una re-lectura del idealismo alemán (Kant, Fichte, Schelling y Hegel) mediante Lacan. Como se señalará más adelante, esto supone el proyecto filosófico de la Escuela eslovena. Un núcleo nuevo que, como señala Ernesto Laclau, es "uno de los proyectos teóricos más innovadores y prometedores en el panorama intelectual europeo"s.

El propósito de este artículo no es hablar únicamente de Slavoj Žižek, sino de tomar como pretexto la importancia de su libro y de su obra para introducir a la lectura de los otros dos autores que componen este libro. ¿Qué habría en común entre ellos? En primer lugar, una ciudad y un contexto: Liubliana y la independencia de Eslovenia de la República Democrática Federal de Yugoslavia en 1991. En segundo lugar, algo mucho más interesante: ciertas operaciones filosóficas inscritas en distintas superficies del saber (filosofía, literatura, cultura pop, teología o ciencia).

La tesis de este texto es la siguiente: hay una Escuela eslovena. Tesis que puede ser declinada así: es a través de un autor que es posible leer las consecuencias de otro autor esloveno. No se trata únicamente de Hegel con Lacan (y lo contrario), sino de leer mejor a Žižek con Mladen Dolar, o a Alenka Zupančič con Žižek. Esto supone lo siguiente: hay un sujeto esloveno, denominado por ellos mismos como la troika. Hay otro supuesto: la filosofía y su diálogo se trata más bien de lecturas e inscripciones de letra sobre

S. Žižek, Le plus sublime des hystériques Hegel passe, París, Point hors ligne, 1988. Después reeditada en 2011 en la editorial Presses Universitaires de France, bajo la dirección de Laurent de Sutter, en la colección Travaux Pratiques y con un nuevo subtítulo: Hegel con Lacan. Existe traducción al español: S. Žižek, El más sublime de los histéricos, Buenos Aires, Paidós, 2013.

6 S.Žižek, ;Goza tu sintoma! Jacques Lacan dentro y fuera de Hollywood, Buenos Aires, Nueva visión, 1994.

S. Žižek, Todo lo que usted siempre quiso saber sobre Lacan y nunca se atrevió a preguntarle a Hitchcock, Buenos Aires, Manantial, 1994.

8 E. Laclau, "Prefacio", en S. Žižek, El sublime objeto de la ideología, México, Siglo XXI, 1992, p. 15. otra letra; en el caso de nuestro sujeto esloveno, de una escritura -anterior-intervenida por la escritura de Lacan.

\section{Una Escuela eslovena: breve contexto e historia}

Partiremos entonces de que hay una Escuela eslovena y que ella aparece, a manera de una fenomenología, con la popularidad de Slavoj Žižek. No obstante, nos parece imposible que la emergencia de su pensamiento fuera sin sus colegas eslovenos. Para llegar aquí nos parece importante trazar elementos históricos mínimos.

Todo comienza probablemente a mediados de la década de los 1960, cuando se funda la revista alternativa Problemi. Esta revista, de un talante crítico y de opinión divergente, es creada como contrapeso a la versión $m a-$ instream titulada Titoist. Así, Problemi fue una revista que acogió artículos que comprendían contribuciones que iban del nacionalismo al marxismo pasando por el lacanismo, el liberalismo y la social democracia. En la década de los 1980, la revista sufre una crisis interna al consejo editorial, de manera que gran parte de sus miembros se adhieren a la nueva revista Nova revija en 1981. Rado Riha, Slavoj Žižek y Mladen Dolar así como otros filósofos de Liubliana toman gradualmente la revista Problemi como una plataforma para sus actividades. Por ejemplo, la organización del primer seminario público de Jacques-Alain Miller, Gérard Miller y Alain Grosrichard para continuar en su posición "lacaniana ortodoxa", así como el lanzamiento de la editorial Analecta como parte del proyecto de traducir una gran cantidad de filósofos clásicos y contemporáneos al esloveno, entre ellos Hume, Spinoza, Kant, Deleuze, Derrida, Lyotard y Badiou. En esa misma época, Žižek fungía como columnista de Mladina, revista cuya orientación política difería de aquella del régimen comunista ${ }^{10}$.

Lo anterior prepara las bases para la fundación de la Sociedad por el Psicoanálisis Teórico en 1982, cuyos tres órganos ejecutivos son desde ese entonces la revista Problemi, la editorial Analecta y Agalma, Instituto para las ideas. Su slogan: "Con nosotros no tienes que gozar" ${ }^{11}$. Este es en general el terreno histórico en el cual emerge la Escuela eslovena. Pero además de la cartografía es importante describir el contexto de Eslovenia entre las décadas de los ochenta y noventa. También es crucial mencionar la toma de posición con Lacan (se trata de esa ortodoxia lacaniana) así como su encuentro con Jacques-Alain Miller, con la École de la cause freudienne y las constantes visitas a París ${ }^{12}$.

S. Žižek y G. Daly, Conversations with Žižek, Cambridge, Polity, 2004, p. 34.

10 En gran parte esto continúa así en 2020 pero con la revista Filozofski vestnik (comunicación personal con Alenka Zupančič y Samo Tomšič).

11 Página oficial de la Sociedad por el Psicoanálisis Teórico, http:// www.drustvo-dtp.si, visto el 10 de junio de 2020, versión inglés y esloveno.

12 Sobre la beca que le otorgó Jacques-Alain Miller a Žižek para dar clases en la universidad Paris VIII, su análisis con él y posteriores desencuentros, recomendamos al lector la introducción del libro Slavoj Žižek de T. Myers (Routledge, Londres, 2003). Sobre las visitas de otros miembros se sabe muy poco. 
Nos referiremos sucintamente a tres cuestiones importantes en lo que concierne al contexto. La primera es el carácter soft del comunismo en la ex-Yugoslavia, país del cual Eslovenia era sólo una de sus provincias. Sólo hasta 1948 Yugoslavia fue estalinista, año en que Tito declara la ruptura. "No alineamiento" es una de las consignas del comunismo titoísta, el cual tenía tres pilares: 1) un sistema político y económico basado en la autogestión; 2) la construcción de una identidad yugoslava; $y, 3$ ) una política internacional que no se alineaba ni a los países de occidente (OTAN) ni a los países comunistas (Pacto de Varsovia). No obstante, este comunismo no fue menos cruel con sus adversarios, especialmente los estalinistas. Como la antigua Unión de Repúblicas Socialistas Soviéticas (URSS), Yugoslavia realizó un esfuerzo de colectivización forzada entre 1949 y 1953. Pero, a diferencia de la URSS, este esfuerzo fracasó y terminó en una política de liberalización. Estos dos elementos posibilitaron una porosidad más alta en la frontera entre la Europa occidental y Eslovenia, que a su vez explica la amplia exposición que tuvo la Escuela eslovena a la cultura occidental (particularmente el cine de Hollywood) y la facilidad para que sus miembros visitaran París para estudiar psicoanálisis ${ }^{13}$.

El segundo punto es la emergencia de la Escuela Eslovena como parte del movimiento cultural NSK (Neue Slowenische Kunst en alemán o Nuevo Arte Esloveno en español) ${ }^{14}$. La vanguardia artística de NSK surge en el umbral de la muerte de Tito para luego ser configurada por la desintegración de la ex-Yugoslavia. Se trata de un colectivo cultural cuya organización estaba divida en diversos campos: diseño, filosofía, literatura, pintura, teatro y música experimental. El producto cultural más conocido es la banda de rock llamada Laibach, que refiere al nombre que le dieron los alemanes a Liubliana durante la ocupación nazi. Es imposible que la Escuela eslovena pudiera concebir una nueva lectura de las operaciones ideológicas sin la reflexión filosófica, las experimentaciones artísticas y los performances realizados por este colectivo. "Hoy Laibach es más pertinente que nunca" se lee en el prólogo de SOI. Un ejemplo: la sobreidentificación, operación que consiste en hacer insoportable la verdad de una formación ideológica identificándose plenamente con ella. Dos muestras: 1) tomar al pie de la letra el reglamento de una institución de tal manera que haga imposible su funcionamiento (ser demasiado honestos, no iniciar un proceso hasta que se termine otro, seguir un reglamento inflexiblemente, etc.);

13 Para una lectura más amplia y profunda del contexto histórico de la ex-Yugoslavia y su vínculo con la Escuela eslovena recomendamos el primer capítulo del libro de I. Parker, Slavoj Žižek. A Critical Introduction, Londres, Pluto Press, 2004. Para una produndizar sobre el mismo punto, y para no centrarse únicamente en la filosofía de Žižek sino también en la de Dolar y Zupančič, está el libro de J. Irwin y H. Motoh titulado Žižek and his Contemporaries. On the Emergence of the Slovenian School, Londres, Bloomsbury, 2013. El libro incluye sendas entrevistas a Zupančič y Dolar.

14 Para abundar en las interesantes conexiones entre NSK y la Escuela esolvena, remitimos al lector nuevamente al libro de I. Parker, op. cit. y al sorprendente libro de A. Monroe titulado Interrogation Machine: Laibach and NSK, MIT Press, Cambridge, 2005 publicado en la colección Short Circuits dirigida por Slavoj Žižek. y 2) la vestimenta, melodía y gestos nazis (o católicos o democráticos) de la música de Laibach.

Finalmente, la tercera cuestión es la llamada "primavera eslovena". En la década de los ochenta emerge, a la par de los distintos movimientos culturales mencionados -NSK, Nova revija-, el liderazgo de una facción reformista en el Partido Comunista de Eslovenia. Esto en el marco del debilitamiento de los países comunistas en general y la inminente disolución de Yugoslavia. Tras un brevísimo conflicto armado llamado "la guerra de los diez días", Eslovenia declara su independencia en diciembre de 1991, misma que fue posteriormente reconocida por la Unión Europea el 15 de enero de 1992. La importancia de la independencia de Eslovenia no debe ser leída a la manera liberal: mayor libertad de prensa, apertura política, estado de bienestar, etcétera. Justo ocurre lo contrario, la Escuela eslovena encuentra las mismas operaciones ideológicas tanto en el discurso estalinista como en el mundo occidental donde se declara el fin de la historia y de la ideología. De ahí el repudio de Žižek por Vaclav Havel, el primer ministro de la República Checa en la era poscomunista tan aclamado por los países de Occidente ${ }^{15}$. En esa década, los noventa, proponer cualquier proyecto alterno al capitalismo o la mínima disidencia al sistema democráticoparlamentario era acusada de llevar a lo peor, y lo peor tenía un nombre: totalitarismo. Con esa misma agudeza, la Escuela eslovena leía un "racismo reflexivo"16 por parte de la recién nacida Unión Europea hacia Europa del Este. Así mismo, ellos ubicaban una geografía del racismo que no estaba localizada: para los sirios Turquía es percibida más europea, mientras que para los griegos Turquía no es europea. En esa lógica Grecia es mucho menos europea que Austria y la última en menor grado que Alemania. Al final uno no encuentra en qué país o región localizar el punto de la verdadera "europeidad". Esta lectura es afinada mediante el concepto de fantasma en Lacan ${ }^{17}$. Un último ejemplo: las lecturas de la Escuela eslovena contestaban la visión estándar de la "balcanización" o del fundamento religioso o étnico ${ }^{18}$ de la Guerra

"Esta es entonces la tragedia de Havel: su postura ética devino en un dialecto moralizante y cínico que fue apropiado por los malandrines del capitalismo. Su inconsistencia heroica de hacer lo imposible (oponiéndose al aparentemente invencible régimen Comunista) terminó sirviendo a aquellos que «de manera realista» argumentan que cualquier cambio real en este mundo es imposible. Esta inversión no es una traición a su postura ética inicial, es inherente a la postura de Havel. La lección última de la tragedia de Havel es entonces inexorable: la fundación ética de la política tarde o temprano termina en su propia caricatura, adoptando el cinismo al cual se opuso en un principio", S. Žižek, "Attempts to Escape the Logic of Capitalism", en London Review of Books, 28 de octubre de 1999 (traducción de los autores), https://www.lrb.co.uk/the-paper/v21/n21/slavoj-zizek/ attempts-to-escape-the-logic-of-capitalism, recuperado el 30 de agosto de 2020.

16 S. Žižek, The Fragile Absolute. Why is Christian Legacy Worth Fighting For?, Nueva York, Verso, 2001, p. 7.

17 Esta geografía del racismo y su conexión con el concepto de fantasma se halla en el artículo de Žižek "You May!", London Review of Books 21, No. 6, 1999, https://www.lrb.co.uk/the-paper/v21/n06/ slavoj-zizek/you-may!?referrer=https $\% 3 \mathrm{~A} \% 2 \mathrm{~F} \% 2 \mathrm{Fwww}$.google. com $\% 2 \mathrm{~F}$, recuperado el 30 de agosto de 2020.

18 "Amenazados por el nacionalismo serbio, incluso el nacionalismo esloveno y croata mantuvieron el respeto por la Yugoslavia de Tito, en cualquier caso por su principio fundamental: aquél de una federación de estados igualitarios con una plena soberanía, incluyendo el 
de Bosnia entre 1992 y $1995^{19}$. Su fundamento es económico y sólo se mistificaría mediante una explicación religiosa y psicologizante, no sin la ayuda de un supuesto humanitarismo que incluía desde la ONU hasta distintos grupos de música pop (U2 y Sting específicamente).

\section{Hay una Escuela eslovena de filosofía}

Pero, ¿qué es lo que justifica el nombre "Escuela eslovena" y por qué esta nominación comporta un elemento fundamental de nuestra lectura? De manera primordial este rótulo se explica por una tradición que comienza con una presentación de Ernesto Laclau en el prólogo a SOI, la autonominación de Žižek y algunos elogios de Alain Badiou ${ }^{20}$. Pero no se trataría únicamente de una inercia al nombre o un reconocimiento mediante loas, sino que esta nominación significa que bajo ese rótulo existen una serie de rasgos, operaciones y lecturas de pensamiento que atravesaría a todos sus miembros. Más aún, que se trataría de un sujeto esloveno. Sujeto en el sentido de un pensamiento que es diagonal a los individuos y que se construye de manera impersonal, de un sujeto en tanto sujetado a la transindividualidad de un discurso. Recordemos incluso que "sujeto" en inglés (subject) o francés (sujet) quiere decir "asunto" o "materia".

Comenta Žižek, burlándose de la manera en que algo que es aparentemente enorme, se reduce esencialmente a un tres que oculta una nada ${ }^{21}$ :

Muchos de mis amigos piensan que si existe una Escuela eslovena y que publicamos tanto fuera de nuestro país, entonces se preguntan ¿qué habría en su centro? La respuesta es nada, absolutamente nada ${ }^{22}$. Esto lo digo en el sentido trágico. Es casi como si nos sorprendieran con los panta-

derecho a separarse. Quien quiera pasar por alto esto, quien quiera reducir la guerra de Bosnia a una guerra civil entre varios «grupos étnicos», toma inmediatamente la postura de los serbios" (traducción de los autores), S. Žižek, "Ethnic Dance Macabre", en The Guardian Manchester, 28 de agosto de 1992. Disponible en https://www.lacan. com/zizek-ethnic.htm, recuperado el 10 de junio de 2020.

19 Para una versión sintética y puntual sobre esta cuestión considérese el capítulo "Yugoslavia/Nationalism" de Katerina Kolozova en R. Butler (ed.), The Žižek Dictionary, Londres, Routledge, 2014, pp. 269-272.

20 "En verdad, existe otro Kant, dramatizado, modernizado, desplazado hacia la política contemporánea y hacia la enseñanza de Lacan. Un «Kant con Marx y Lacan», que es una creación eslovena. Hay que saludar a la Escuela eslovena de filosofía, totalmente original, y de la que soy interlocutor, con gran placer, desde hace muchos años. Como toda Escuela verdadera, conoció escisiones y animosidades. Pero yo, lejos de Liubliana, puedo saludar al menos una vez, conjuntamente, a Rado Riha, a Jelica Šumič, a Slavoj Žižek, a Alenka Zupančič y a todos sus amigos. Es a esta Escuela a la que le debemos una visión enteramente nueva del gran idealismo alemán, en sintonía con una teoría política posmarxista (todos estos pensadores eslovenos participaron, a su modo, en la Yugoslavia socialista, y todos ellos fueron lectores de Althusser), teoría política que depende, a su vez, de una lectura de Lacan cuyo efecto se centra, no tanto en la fuerza del lenguaje como en el insostenible resplandor de lo real", A. Badiou, Lógicas de los mundos. El ser y el acontecimiento 2, Buenos Aires, Manantial, 2008, p. 590.

21 S. Žižek y G. Daly, Conversations with Žižek, Cambridge, Polity, 2004, p. 37 (traducción de los autores).

22 Aquí la "nada" tiene un peso lacaniano, a manera de un vacío central en el que gira un cártel lacaniano. lones abajo cada vez que alguien nos visita en Liubliana y les tenemos que decir que nada ocurre aquí. Somos únicamente tres amigos que nos reunimos y eso es todo. Allí tienes nuevamente tu troika estalinista estilo KGB -ya sabes, los comunistas estaban siempre organizados como troika, para liquidar gente o para lo que sea-. Se trata estrictamente de una troika con Alenka Zupančič, Mladen Dolar y yo.

En lo que concierne al prólogo de Laclau, hay dos características que suponen dos de los rasgos más distintivos de esta Escuela, resumidos por el argentino de esta manera $^{23}:$ 1) la insistencia en la teorización del concepto de ideología con el arsenal conceptual del psicoanálisis, y 2) la extensión de este arsenal para la lectura de filósofos clásicos (Platón, Descartes), del idealismo alemán (Schelling, Kant), de Marx (el primer capítulo de SOI como gran ejemplo de ello), y especialmente de Hegel.

$\mathrm{Y}$ es que esta articulación de Hegel con Lacan es lo que nos parece fundamental: no sólo Lacan es puesto como la cúspide de la filosofía idealista alemana, sino que podríamos resumir el proyecto filosófico de toda la Escuela eslovena como la lectura psicoanalítica lacaniana de la filosofía hegeliana. Incluso, el término "articulación" podría ser algo deficiente para exponer los alcances de esto. "El núcleo de todo mi trabajo es usar a Lacan como una herramienta intelectual privilegiada para reactualizar el idealismo alemán" 24 , es la manera en que el propio Žižek prefiere formularlo. De manera tal que leer a Hegel con Lacan supone exponer las profundas consecuencias del proyecto lacaniano (en tanto fidelización y resurrección del evento freudiano ${ }^{25}$ ) como continuación del legado de Hegel en la filosofía occidental. Žižek leería en el idealismo alemán el antecedente lógico de Lacan que sólo podría actualizarse a través de hacer legibles esas trazas del idealismo por medio del propio Lacan y del trabajo de Freud. Anticipación y retroacción es el movimiento circular de actualización. Lacan como la cúspide del idealismo alemán, el idealismo alemán como traza actualizable por el psicoanálisis lacaniano. Žižek como el mediador evanescente ${ }^{26}$.

Como ya lo habíamos anunciado, el hecho de que hay una Escuela eslovena implica que uno puede leer mejor las consecuencias de un autor a través de otro. En esto residiría la importancia de la Escuela eslovena como un sujeto esloveno, es decir, como pensamiento diagonal, impersonal y transindividual. O lo que es lo mismo: el "hay" es correlativo a un pensamiento colectivo donde leer a Žižek con Dolar haría más legible una operación filosófica en Žižek, o leer a Zupančič con Žižek despejaría otra operación filosófica al mostrar que tal operación fue realizada en otros corpus de saber. No se trataría únicamente de una construcción en conjunto, sino de que un autor llevaría más lejos lo que incipientemente está en otro autor. O mejor aún, un autor cir-

\footnotetext{
E. Laclau "Prefacio", en S. Žižek, op. cit., pp. 13-15.

24 E. Wright y E. Wright (eds.), The Žižek Reader, Oxford, Blackwell, 1999, p. ix (traducción de los autores).

25 Tal como lo expone Žižek en En defensa de las causas perdidas, Madrid, Akal, 2011, p. 397.

26 "Mediador evanescente" es justo el término que el propio Žižek utilizó a principio de los años noventa y que toma prestado de Fredric Jameson. Cf. F. Jameson, "The Vanishing Mediator; or, Max Weber as Storyteller", en New German Critique 1, 1973, pp. 52-89.
} 
cunscribe un agujero o atolladero de manera más ceñida que otro pero no sin el otro. Lo que nosotros llamamos sujeto esloveno y que se desprende del hay una Escuela eslovena y que ha sido llamada troika, es también una comunidad filosófica. Esto lo confirma Žižek asíi ${ }^{27}$ :

En este sentido, así es como trabajamos (la troika con Mladen Dolar y Alenka Zupančič). Esta es mi idea de una comunidad filosófica. Hablamos mucho, discutimos, pero en último término estamos solos y esto funciona perfectamente bien, yo creo. No hacemos talleres juntos. Cuando necesitamos hablar, hablamos. Hay una antigua fórmula romántica: una verdadera compañía es cuando puedes compartir la soledad, o una mierda así. Así es como funcionamos.

Esta forma de trabajo podría explicar la conocida práctica del "autoplagio" de Žižek -los mismos pasajes en varios libros, práctica comentada más adelante en este texto-, a su vez impediría acusar de robo de ideas a cualquiera de ellos en caso de no citar a su colega de Escuela. Por ejemplo, la lectura del panóptico de Božovič (para mostrar que este dispositivo todo lo ve pero es impotente para impedir un acto), el chiste de "un café sin leche" que Zupančič retoma del filme Ninotschka de Lubitsch (para hablar de la "diferencia mínima" que no es simbólica sino real, en el sentido lacaniano), la interpasividad teorizada por Robert Pfaller (para explicar cómo delegamos nuestras actividades al gran Otro), la "eutanasia de la razón" de Joan Copjec (para encontrar en Kant dos formas de hacérselas con los callejones sin salida de la identidad, lo que llevaría a una lectura filosófica de las fórmulas de la sexuación), la voz o la mirada como "órgano sin cuerpo" en Mladen Dolar (para describir cómo a un agujero que se encuentra "negativizado" tiene como correlato un objeto sin cuerpo que está en "exceso", lo que llevará a dos materialismos: uno del vacío y otro de lo incorpóreo), la profundización de homología estructural Marx-Lacan y la ciencia moderna como inestabilidad de Samo Tomšič o la lectura de los semblantes de Jelica Šumič (para aclarar cómo las apariencias tienen un peso ontológico $)^{28}$. Nuestro lector podrá corroborar cómo todas estas referencias (y otra más)

27 S. Žižek y G. Daly, Conversations with Žižek, Cambridge, Polity, 2004, p. 42 (traducción de los autores).

28 Dado que introducimos nuevos nombres asociados a operaciones específicas, nos resulta importante hacer una distinción entre la Escuela eslovena, la troika y sus "interlocutores mudos". La troika se refiere únicamente a Alenka Zupančič, Mladen Dolar y Slavoj Žižek (Slavoj Žižek y Glyn Daly, op cit., p. 34). La Escuela eslovena podría incluir nombres de fundadores (Rastko Močnik, Miran Božovič, Rado Riha, Zdravko Kobe, Renata Salecl y Jelica Šumič) y filósofos de una generación más joven (Peter Klepec, Samo Tomšič, Andreja Zevnik, Gregor Moder o Jure Simoniti). Finalmente, estarían los "interlocutores mudos", es decir, aquellos filósofos que aportaron nuevas operaciones, que tienen un mismo estilo de lectura y que son cercanos a la Escuela eslovena (Eric Santner, Joan Copjec y Robert Pfaller). Es posible todavía encontrar artículos recientes de la Escuela eslovena en la revista internacional Filozofski vestnik (a cargo del Instituto de filosofía de la Academia Eslovena de Ciencias y Artes). Sobre los artículos de la troika y los "interlocutores mudos" existen (y existieron) varios proyectos editoriales en donde Slavoj Žižek ha sido el editor: Short Circuits (MIT Press), SIC (Duke University Press), Wo es War (Verso). Si se quiere echar un vistazo o profundizar en los autores que influyeron a la lectura lacaniana de la troika se puede consultar Jacques Lacan: Critical Evaluations in Cultural son implícitas y constantes entre ellos. Por esta razón no hay motivo para afirmar que hay plagio sino más bien repetición de gestos y contenidos, los cuales son tensados, releídos, apropiados y redimensionados por cada uno de ellos y entre ellos. Es interesante que aunque se trate de un pensamiento impersonal y colectivo, queden huellas de su rúbrica ${ }^{29}$. Por ahora no nos interesa el estilo de cada uno sino justo aquello que los atraviesa.

Si postulamos que hay una Escuela eslovena no lo decimos en el sentido de "escuela" psicoanalítica (transmisión del psicoanálisis, forma de concebir la clínica, dispositivos como el pase o el cártel ${ }^{30}$ ), que es a su vez una apropiación y reformulación de las escuelas helénisticas -epicureismo, cinismo y hedonismo-como formas de articular saber, lazo social y forma de vida. Decimos "Escuela" de la misma manera en que se dice "Escuela de Frankfurt" (un grupo de filósofos, intelectuales y científicos que compartirían un estilo de hacer filosofía). Lo decimos como una forma de desacademizar su investigación, pero también para hablar de un "sujeto" impersonal. Las consecuencias de ello es que no es posible localizar ni un solo concepto de la Escuela eslovena. Si bien "sobreidentificación", "mirada de paralaje" o "menos que nada" son términos que están asociados con Žižek o la Escuela eslovena, no son estrictamente conceptos. Aclaremos: la Escuela eslovena toma prestado conceptos, opera en ellos, les imprime una nueva lectu$r a$, pero estos conceptos no son suyos, sino de Lacan, de Hegel, de Marx o de Althusser. Entonces, ¿dónde radica la originalidad de esta Escuela filosófica? O, para retomar nuestra pregunta inicial, ¿en dónde está la novedad de $S O I$ ?

Uno de los problemas que encontramos en la apropiación académica anglosajona es el intento de captura de un filósofo por medio de un concepto. Concepto que luego es explotado y popularizado al punto en que el autor queda reducido a él. Pensemos en Giorgio Agamben y el homo sacer, Julia Kristeva y lo abyecto, Roberto Esposito y la biopolitica inmunitaria, Judith Butler y el género performativo, Achille Mbembe y la necropolitica, Alain Badiou y el acontecimiento, Jacques Derrida y la deconstrucción, Jean-François Lyotard y la muerte de los grandes relatos, Gayatri Spivak y la subalternidad, Luce Irigaray y la otra mujer, Catherine Malabou y la plasticidad o Barbara Cassin y los intraducibles. Por academia anglosajona entendemos a las universidades del Reino Unido y de Estados Unidos, pero también el sistema académico formal y hasta informal de congresos, coloquios, escuelas de verano que tienen lugar en Europa (Berlín, Ámsterdam, París, Roma o pequeñas ciudades universitarias) y que reproducen universidades de países del llamado "Sur Global"31. Es probable

Theory (Routledge, 2003, cuatro tomos: Teoría psicoanalítica y práctica; filosofía; sociedad, política, ideología; y, Cultura).

29 Una tesis central del libro ¿Robo de ideas?: Wilhelm Fliess, su plagio y Freud de Erik Porge es que siempre que hay robo de ideas queda una rúbrica del estilo del autor (Kliné, Buenos Aires, 1998).

30 Como serían la École lacanienne de psychanalyse, la École de psychanalyse des Forums du Champ Lacanien o la École de la cause freudienne, es decir, una Escuela es diferente a un Instituto, Foro, Asociación, Sociedad, Institución o Grupo psicoanalítico.

31 Bruno Bosteels señala cómo en Latinoamérica fue traducido Badiou desde los años sesenta y ahora parece que Badiou es el nuevo filó- 
que esta apropiación académica tenga su resorte en una especie de extractivismo del saber exótico de la última novedad europea o venida del "Tercer Mundo", que es apuntalada y trabajada por la academia anglosajona, para luego serle regresada a sus países de origen ${ }^{32}$.

A pesar de que han proliferado los libros que hablan de la filosofía de Žižek, no pueden capturar un solo concepto en su obra. Por esta razón terminan hablando de la filosofía de Hegel, el psicoanálisis de Lacan o el pensamiento de Marx. En otras ocasiones son síntesis de las ideas que desarrolla en sus libros, cuáles son los temas que han cambiado a lo largo de su obra o haciendo de sus ejemplos una especie de concepto: desde los excusados europeos hasta Kung-Fu Panda, pasando por los Tamagochi, los Kinder sorpresa o el café sin leche. Otras veces se centran en un tema específico -la política, la teología, la ideología, el cine- planteando las problematizaciones o lecturas que hace el esloveno pero sin poder capturar un solo concepto. Por nuestra parte, no queremos ni capturar un concepto - lo cual nos resulta imposible por la propia naturaleza de su filosofía- ni extraer algún saber para ponerlo a circular en la academia anglosajona - a cambio de capitalizar ese saber por un lugar de expertos-, sino de dar cuenta de qué es lo que está en juego en la filosofía de Žižek, y por extensión, de la Escuela eslovena.

Encontramos que los comentaristas tienen tres posiciones: 1) se intenta aprehender un pensamiento o una serie de conceptos que supondremos hallan en la Escuela eslovena ${ }^{33}$; 2) piensan la filosofía de un autor como una teoría o como un pensamiento que estuviese unificado y al que luego se le aplica una crítica ${ }^{34}$; o 3) esta teoría o pensamiento es aplicada a otro saber como el cine,

sofo de moda justo porque nos llega de la academia estadounidense. Cf. "prólogo" en A. Badiou, El cine como acontecimiento, México, Paradiso/Universidad Iberoamericana, 2016. A esto deberá agregarse que antes de que Badiou fuera traducido al inglés en 2003, ya circulaba en Argentina y en México libros como Manifiesto por la filosofia, El ser y el acontecimiento o Condiciones a finales de los noventa. Finalmente, se suele pasar por alto que Slavoj Žižek visitó dos veces en los noventa la Ciudad de México invitado por Néstor Braunstein, quien es padrino del hijo de Žižek con Renata Salecl. Cuando hoy se le quiere invitar a México para que imparta conferencias se olvida que ya en los noventa Žižek era conocido en México, esto además coincide con que las fechas de las primeras traducciones publicadas del esloveno justamente hechas por la hija de Néstor Braunstein. En nuestra opinión, todo este efecto de aparente "novedad" está relacionado con la captura de un concepto por la academia anglosajona. Hasta ahora el único libro que ha abordado sistemática y rigurosamente la obra de Žižek ha sido el de Santiago Castro-Gómez (Revoluciones sin sujeto. Slavoj Žižek y la crítica del historicismo posmoderno, México, Akal, 2015), donde el autor intenta desmitificar al rockstar (de gestos ocurrentes, bromas escatológicas, comentador de películas populares, etc.) para tratarlo como un pensador, como un filósofo.

32 Es lo mismo que sugiere François Cusset de los filósofos franceses de posguerra, pero sin problematizar la parte extractivista cuando habla de cómo Derrida, Deleuze, Foucault o Lyotard fueron construidos en Estados Unidos y luego regresados a París bajo la forma de filosofías bien hechas y bien construidas. Cf. F. Cusset, French Theory, Tenerife, Melusina, 2005.

33 Por ejemplo: A. Johnston, Žižek's Ontology: A Trascendental Materialist Theory of Subectivity. Illinois, Northwestern University Press, 2008; T. Myers, Slavoj Žižek, Londres, Routledge, 2003.

34 Por ejemplo: I. Parker, op. cit.; S. Kay, Žižek: A Critical Introduction, Cambridge, Polity, 2003; M. Pond, Žižek: A (Very) Critical Introduction, Cambridge, Eerdermans, 2008. la política, la teología, los medios de comunicación, la ética o la ontología ${ }^{35}$. Estas tres posiciones tienen como causa un abordaje típico anglosajón de asir un pensamiento identificándolo a un autor ${ }^{36}$.

\section{Rasgos, operaciones y lecturas}

Expuesta la cuestión del abordaje anglosajón, común entre la mayoría de comentaristas de la obra de Žižek y de la Escuela eslovena ${ }^{37}$, optamos por proponer una lectura de la filosofía de esta Escuela por medio de sus rasgos, operaciones y lecturas. Argumentamos entonces, que más importante que el uso de conceptos prestados de otros filósofos -reapropiados, renovados o torsionados-, la originalidad de la Escuela eslovena son estos tres componentes.

\subsection{Rasgos}

Entendemos como los rasgos de la Escuela eslovena su estilo de escritura y exposición de ideas, mismo que supone lo primero con lo que se encuentra un lector novel de estos autores, esté sumergido en el psicoanálisis y la filosofía o no. Identificamos tres principales: 1) adopción de ejemplos provenientes de la cultura popular, 2) una aparente "inestabilidad" temática o falta de circunscripción en un solo tema de discusión, y 3) la constante repetición de ejemplos o hasta fragmentos en una u otra obra.

Una de las razones por las que Žižek es sumamente popular más allá de los círculos académicos del psicoanálisis, el marxismo y la filosofía hegeliana -los cuales no suelen ser muy accesibles- es por el uso de tantos ejemplos de la cultura popular, desde películas de Disney hasta productos de la comida chatarra. Su extrovertida personalidad y apariencia acentúan aún más esta dimensión ${ }^{38}$. En entrevistas, ha admitido que este procedimiento es, en buena medida, para que él mismo comprenda los densos conceptos ${ }^{39}$, o como lo hace en su

35 Por ejemplo: A. Kotsko, Žižek and Theology, Londres, T\&T Clark, 2008; M. Sharpe y G. Boucher, Žižek and Politics: A Critical Introduction, Edimburgo, Edinburgh University Press, 2010; P. Taylor, Žižek and the Media, Cambridge, Polity, 2010.

36 Un ejemplo nos ayudará a aclarar este punto y a apuntalar nuestra lectura: la izquierda lacaniana. Existen dos grandes libros que tratan sobre este interesante sintagma: el de Yannis Stavrakakis y el de Jorge Alemán. Mientras que el primero toma por sentado que hay una "izquierda lacaniana", y la aborda identificando conceptos y teorías a un autor (Badiou, Castoriadis, Laclau, Žižek), lo que podríamos señalar como ejemplo de abordaje anglosajón; el segundo considera que "izquierda lacaniana..." (con puntos suspensivos a manera de un matema) es una conjetura que hay que probar y que no está supeditada ni a conceptos ni a autores, sino a una lectura de la izquierda a través de Lacan y a lo que nosotros llamamos operaciones. Cf. Y. Stavrakakis, La izquierda lacaniana. Psicoanálisis, teoría, política, Buenos Aires, Fondo de Cultura Económica, 2010 y J. Alemán, Conjeturas sobre una izquierda lacaniana, Buenos Aires, Grama, 2013.

7 J. Irwin y H. Motoh, op. cit.

38 Quizá prueba de ello es incluso ser el objeto de un video musical paródico de su paisano comediante, Klemen Slakonja. Cf.: https:// www.youtube.com/watch? $\mathrm{v}=80 \mathrm{X} 0 \mathrm{pbCV}$ _t 4 . Recuperado el $12 \mathrm{de}$ junio de 2020.

39 Una entrevista donde Žižek explica un poco su manera de trabajar está en Enjoy your Žižek, R. S. Boyton, 2001. Disponible en: https:// www.lacan.com/zizek-enjoy.htm (recuperado el 13 de junio de 
autoentrevista en Las metástasis del goce, para ponerse en la posición de un Otro ignorante. Esta característica no es exclusiva de Žižek, sino que la encontramos también en Alenka Zupančič y en Mladen Dolar ${ }^{40}$.

Así como la cultura popular bombardea exigiendo una hiperactividad de consumo de gadgets, productos y nuevas identidades, relegándonos a una hiperactividad sumamente pasiva, así notamos como rasgo la dificultad (en apariencia) de hallar un objeto claro de discusión en los textos de la Escuela eslovena. Para quien apenas se involucra en la lectura de Žižek, Zupančič o Dolar, pronto queda claro que no está hallando una estructura académica clásica con la presentación de una hipótesis, un aparato teórico y un análisis con una metodología explícita. Iniciando con la descripción de una escena de películas, un eslogan del Partido Comunista Chino, una anécdota de la infancia, un poema medieval o un hecho político que pasó medianamente desapercibido, y atravesando todos ellos a lo largo cada texto, tal pareciera que la Escuela eslovena "habla de todo y no habla de nada"41.

Por supuesto, rechazamos esta postura por varias razones. Primero, porque simplemente está equivocada. Es evidente que hay un claro punto que se discute y elabora en cada libro. Tómese, a modo de ejemplo, los títulos de los capítulos de En defensa de las causas perdidas, y nótese que están divididos en sus dos conceptos principales, ya sea para ironizar por la (en apariencia) distancia que separaría ambas ideas ("Felicidad y tortura en el mundo atonal", ¿qué relación podía tener la felicidad con la tortura?; "El estalinismo revisitado o sobre cómo Stalin salvó la humanidad del hombre", ¿cómo podría un dictador sanguinario como Stalin procurar la humanidad del hombre?); o para plantear cómo un concepto clave se manifiesta en lugares dispares ("El terror revolucionario desde Robespierre hasta Mao", donde el terror revolucionario se manifiesta en distintas concepciones políticas; "Alain Badiou o la violencia de la sustracción", donde se señalan los impasses de la filosofía política de Badiou a través del concepto de la sustracción). Es decir, el propio título no es azaroso, sino

2020). En una entrevista para la televisión presentando el libro The Puppet and the Dwarf, se burla del presentador de televisión que se queja de lo complicado del libro: "Qué raro, el punto era que Lacan fuera alguien a quien incluso tu abuela entendiera”. Disponible en: https://www.youtube.com/watch?v=KjEtmZZvGZA (recuperado el 13 de junio de 2020).

40 El uso de la cultura pop es menos prolífero pero no por ello menos central. Recordemos el uso que hace Zupančič del gag "Who's on first" o el chiste sobre Bush y Condoleezza Rice en su libro Sobre la comedia. En el caso de Dolar mencionaremos la anécdota "Que bella voce" al inicio de Una voz y nada más o su tripartición de la humanidad en oficinista, deshollinador y mucama.

41 Tony Myers, uno de los primeros comentaristas de Žižek, explica así el interés del esloveno por la cultura pop: "Si Žižek analiza los desechos de la cultura sin una perspectiva rigurosa, si, en otras palabras, su teoría es «baja» como sus temas, el proyecto de Žižek sería por completo aburrido e indiferente. Nuestra fascinación inicial por el trabajo de Žižek procede justamente de la mezcla e intercambio de registro, de decir lo que lo que la filosofía no debería de decir. Esto es análogo a la manera en que, a mediados del siglo XIX, los escritores como el poeta francés Baudelaire (1821-1867), comenzaron a utilizar la sinestesia. La sinestesia es la descripción de un sentido en términos asociados a otro sentido, como «escucho al azul» o «veo las cosas muy ruidosas». La sinestesia sólo puedo ser establecida como una práctica bajo el trasfondo en el cual los poetas románticos concibieron como la decepción de los insípidos y mundanos sentidos individuales", T. Myers, op. cit., p. 3 (traducción de los autores). que señala un concepto clave de lectura que se elaborará en diferentes ejemplos y casos a lo largo de todo el capítulo.

Segundo, se debe rechazar la idea ingenua de que "se habla de todo y no se habla de nada" respondiendo a una segunda crítica -que corresponde al tercer rasgo hallado-, a saber: la constante repetición de ejemplos a lo largo de los textos. Como ironiza Todd McGowan -un claro defensor de la Escuela eslovena- a veces desearíamos que la computadora de Žižek no tenga la función de "copiar y pegar" el propio McGowan señala cómo, al recurrir a un mismo ejemplo - analizar una y otra vez, en varios libros y ensayos, una misma escena de David Lynch-, el asunto es notar que a pesar de ser la misma escena, se movilizan diferentes interpretaciones, señalando la riqueza de la escena misma. O como el propio Žižek distingue, en Less than Nothing ${ }^{43}$, entre el ejemplo idealista y el materialista: desde una postura idealista, ningún ejemplo es suficiente, pues todos cojean en alguna dimensión para capturar la complejidad del concepto que quieren ejemplificar, por ello proponen múltiples ejemplos de toda naturaleza ${ }^{44}$; mientras tanto, la postura materialista recurre al mismo ejemplo una y otra vez, convirtiéndose en un Singular universal: persiste en múltiples configuraciones simbólicas, en muchas ideas, pues en todas ellas el ejemplo puede revelar algo diferente, algo nuevo que en otra configuración está oscuro ${ }^{45}$. Ejemplo de ello es el análisis de Žižek de la escena de Terciopelo Azul donde Jeffrey mira el ataque sexual de Frank sobre Dorothy, o la escena en Freud, pasión secreta que Zupančič usa para comprender la relación entre sexualidad y política, o el uso que hace Mladen Dolar de la tripartición entre oficinistas, deshollinadores y mucamas.

Finalmente, debemos rechazar la idea de que "se habla de todo y no se habla de nada" por todas las operaciones y lecturas que se señalan en el resto de este artículo. Lo que notamos entonces no es la propuesta de un concepto que sea "la llave" para descifrar todo el pensamiento, sino de inversiones, sustracciones, intromisiones, entre otras

42 Cf. T. McGowan, "Introduction: Enjoying the Cinema", en International Journal of Žižekian Studies, Vol. 1, 3 (2007).

43 S. Žižek, Less than Nothing. Hegel and the Shadow of Dialectical Materialism, Londres, Verso, 2012, p. 364.

44 ¿No sería acaso un perfecto ejemplo de esto la obra de Freud? Sus libros más famosos (el de los sueños, el de psicopatología, el del chiste) funcionan a base de múltiples viñetas, decenas de ejemplos, cada uno señalando un aspecto más de la idea abstracta que quiere transmitir en esa obra. ¿No acaso su re-escritura y aportar nuevos ejemplos a lo largo de las ediciones nuevas de sus obras señala esta obsesión por aún no poder hallar el ejemplo adecuado para capturar su idea tan compleja? Diremos que lo mismo sucede también con Lacan cuando habla de la escena que narra San Agustín sobre un niño que mira envidioso a su hermano beber del pecho de su madre, la pesadilla narrada por Freud sobre el hijo que le reprocha a su padre no ver que está ardiendo o el sueño de la inyección de Irma.

45 Otra manera de leer esto es que no se trata de que un ejemplo sirve para explicar "mejor" un concepto muy "complejo" -castración simbólica, tachadura del Otro, el Absoluto- sino que el ejemplo permite dar forma al concepto mismo y con ello revelar los impasses del concepto, atolladeros con los que algo se puede hacer. El ejemplo de las rezadoras en la Ilíada o del chiste de tener sexo con Cindy Lauper -hallados ambos en Cómo leer a Lacan-nos señalan una manera de proceder que podríamos caracterizar como contraintuitiva: invirtiendo a Popper, no se trata sólo de indicar que la evidencia apunta a que sólo hay cuervos negros, sino a preguntarse hasta qué punto el concepto mismo nos está impidiendo encontrar a los cuervos blancos. 
operaciones, que posibilitan una nueva lectura de aquellos principios del psicoanálisis y la filosofía.

\subsection{Operaciones}

Una vez señalados los rasgos que nos parecen más evidentes de la Escuela eslovena, aquellos que se hallan de manera superficial, podemos pasar a entender estas características como posibilitadoras de ciertas operaciones (lógicas, filosóficas, teóricas, metodológicas, psicoanalíticas). ¿Qué es una operación? En matemáticas este término se refiere a la aplicación de un operador sobre los elementos de un conjunto. El operador toma los elementos iniciales y los relaciona con otro elemento de un conjunto que puede ser de la misma naturaleza o no. Existen operaciones internas (dentro de un mismo conjunto) o externas (del elemento de un conjunto sobre elementos de otro conjunto). Existen operadores de orden (mayor, menor), lógicos (conjunción, disyunción, negación) o aritméticos (suma, resta, multiplicación). Las operaciones tienen ciertas propiedades como son la asociativa, conmutativa, transitiva, reflexiva, simetría o elemento neutro. A partir de esta definición matemática de operación, podemos afirmar que una operación es la aplicación de un operador para producir una relación, un reordenamiento diferente entre los elementos de un conjunto. Recordemos también que una de las funciones más importantes de las matemáticas es sustituir la idea de un contenido específico por la de una función operativa, por ello aquí debe leerse como "elemento" un objeto, un párrafo, una palabra, un enunciado, un texto, una persona o cualquier objeto real o imaginario. Las operaciones realizadas por la Escuela eslovena podrían ser la deconstrucción, el corte, la suspensión, la tensión, la sustracción, la identificación, la torsión, entre otras. Tales operaciones relacionan los elementos de manera diferente posibilitando otra lectura.

Es así que en la Escuela eslovena podemos encontrar lecturas que son posibles por operaciones realizadas, pero no encontraremos conceptos o teorías. Esta idea la encontramos también, por ejemplo, en el psicoanalista lacaniano Jorge Alemán a propósito de Žižek ${ }^{46}$ :

Para mí es un performer, alguien que interviene en diversos contextos de la filosofía contemporánea. A diferencia de Badiou o Laclau u otros postestructuralistas, no veo a Žižek con una teoría propia. Él se mantiene todo el tiempo en una puntuación interpretativa de los otros, en una operación après-coup de lo que los otros van diciendo o haciendo. Como si fuera el "más uno" de los contemporáneos, a los cuales tarde o temprano los pasa por la criba de su análisis sintomático. También se podría decir que él se analiza con los contemporáneos, se repite, se plagia a sí mismo, los desjerarquiza buscándoles sus impases. Pero del mismo modo que en un análisis, un discurso aparentemente trascendente del analizante queda socavado desde su interior por un lapsus o un tropiezo, y así Žižek captura una gran teoría y la muestra como un lapsus o un chiste.

\footnotetext{
J. Alemán, "La política en cuestión. Conversación con Diana Plaza Martín y Gibrán Larrauri Olguín”, en Lacan, la política en cuestión... Conversaciones, notas y textos, Buenos Aires, Grama, 2010, p. 100.
}

No lo veo ni como psicoanalista ni como filósofo. Lo veo como un "interventor" incisivo y ocurrente.

Si bien hay rasgos más marcados en algunos autores que en otros, nosotros hacemos esta descripción extensiva para toda la Escuela eslovena. No imaginaríamos a Dolar de bufón, aunque su sentido del humor y su escritura lúdica son dos rasgos constantes en su escritura. Tampoco encontramos la sistematicidad de la escritura de Zupančič en Žižek. Lo que aquí nos interesa es una lectura sintomática que se localiza en un detalle, un pliegue, en un callejón sin salida, es decir, en un síntoma, para posteriormente intervenir ahí.

Identificamos entonces cuatro operaciones: 1) sustracción, 2) intromisión, 3) inversión con vectorización, y 4) redoblamiento de una negatividad con otra.

Iniciemos con la sustracción: operación en la que la huella o marca que queda de haber sustraído un elemento lo vuelve más presente en ausencia. Esta vez el ejemplo viene del cine, a través de la sustracción de la voz. En términos generales, se trata de la típica escena de una película de terror donde se baja el personaje de un auto para entrar a una tienda en una estación de gasolina, dejando a su copiloto escuchando la radio. La escena continúa dentro del auto, de donde sale repentinamente el asesino del asiento trasero para cometer su acto, el sonido de la radio y los forcejeos haciendo mucho ruido. Hay un cambio de plano y el conductor está esperando para pagar sus cigarrillos, en la ventana, detrás de él, se miran los forcejeos del asesino con el copiloto, pero no se escucha nada en este plano. La sustracción de la voz a la mirada acentúa la voz. Lo mismo ocurre cuando en un filme, en medio de una tormenta, se hace un cambio de plano al interior de una casa: por la ventana se tuercen los árboles con el viento creando el mismo efecto: la sustracción del sonido de la lluvia y el viento dejando únicamente la vista de la ventana redobla su fuerza. Esto ocurre también con el cuadro El grito de Munch, donde no hay voz, redoblando el efecto de ese mismo grito (este último movimiento analizado en Enjoy your symptom! $\left.{ }^{47}\right)$.

El movimiento inverso ocurre cuando la imagen es sustraída de la voz, produciendo de esta manera un efecto de redoblamiento de la imagen, un engrandecimiento divino del que habla. Es justo lo que ocurre en El mago de $\mathrm{Oz}$ o en El testamento del Doctor Mabuse de Fritz Lang: al sustraerse de la mirada de los otros -sustraer su imagen-, su imagen queda redoblada a través de un halo de autoridad divina. Estos dos últimos ejemplos los trabaja detenidamente Mladen Dolar de su libro Una voz y nada más ${ }^{48}$ en lo que llama la "voz acusmática" -tomando prestado el concepto de Michel Chion $^{49}$-, es decir, una dinámica entre la sustracción de la voz y su re-localización en un cuerpo. Eso ocurre en el conocido el corte del grito en medio de una escena, pasando a un plano obscuro o a una escena más tranquila: la voz del grito resuena cuando se le sustrae. La operación de la sustracción

\footnotetext{
47 S. Žižek, Enjoy your symptom! Jacques Lacan in Hollywood In and Out, Nueva York, Routledge, 2001, p. 130.

48 M. Dolar, Una voz y nada más, Buenos Aires, Manantial, 2007.

49 M. Chion, La voz en el cine, Madrid, Cátedra, 2004.
} 
es central en la lectura que hace Alenka Zupančič de Nietzsche, donde afirma que el "instante de la sombra más corta" -metáfora que reúne otras metáforas de Nietzsche como "el mediodía", "el fin del más largo error", "punto culminante de la humanidad"- en realidad debe leerse como división o como sustracción ${ }^{50}$. Esta operación de sustracción se le encontrará a lo largo de la obra de Žižek, al punto en que comentadores como Fabio Vighi sostienen que hay dos conceptos fundamentales en la obra del esloveno: mirada de paralaje y sustracción ${ }^{51}$.

La operación opuesta a la sustracción sería la de intromisión: la irrupción violenta de una "mancha de lo Real" en el cuadro o la imagen. Esto lo desarrolla Žižek con bastante claridad en The Fright of Real Tears ${ }^{52}$, a propósito de su reflexión sobre el concepto de sutura, clave para la teoría de cine ${ }^{53}$. Varios ejemplos son tomados de películas de Hitchcock pero dos de ellos resaltan, ambos del filme Los pájaros. En el primer ejemplo, Melanie avanza en la lancha hacia Mitch. Ambos se sonríen. De pronto, un pájaro entra a cuadro y ataca a Melanie, haciéndole sangrar la cara. Una escena romántica súbitamente se resignifica como un ataque violento a la paz del pueblo, tema de la película misma.

En el segundo ejemplo, la intromisión no es sólo una mancha sino una apropiación de la agencia narrativa. En la famosa escena del incendio de la gasolinería, ya que ha iniciado el caos, una toma panorámica desde lo alto nos muestra una visión general del sitio. De pronto, poco a poco, pájaros empiezan a poblar la imagen hasta cubrirla casi toda. Lo que aquí sucede es que un punto de vista de pronto interrumpe la escena que era en apariencia objetiva (una toma panorámica de la estación de gasolina), la cual se lee retroactivamente como una escena vista por un Otro (en realidad, era el punto de vista de los amenazantes pájaros, en el cielo observando el caos). En estos dos casos, lo que genera la operación de intromisión es entender la dimensión temporal de la narrativa cinematográfica como algo contingente y que se crea retroactivamente ${ }^{54}$.

50 A. Zupančič, The Shortest Shadow. Nietzsche's Philosophy of the Two, Cambridge, MIT, 2003, p. 2.

51 F. Vighi, On Žižek's Dialectics. Surplus, Subtraction, Sublimation, Londres, Continuum, 2010. Como hemos dicho a lo largo de este trabajo -y contra lo que afirma este comentador-, consideramos que "mirada de paralaje" es un término prestado del filósofo japonés Karatani, y que además sería más bien una lectura (que tratamos más adelante como mirar torcido). En el caso de "sustracción", no sería para nosotros un concepto sino una operación.

52 S. Žižek, The Fright of Real Tears. Krzysztof Kieslowski Between Theory and Post-Theory, Londres, British Film Institute, 2001. Recién se publicó su traducción: El espanto de lágrimas reales, México, Paradiso/Universidad Iberoamericana, 2020.

53 En este texto, Žižek propone el concepto de interfaz como el mínimo procedimiento de sutura. Quizá sería este un ejemplo que podría desacreditar nuestra hipótesis ("no hay concepto en la Escuela eslovena"), pero tomando en cuenta que parte finalmente del concepto de sutura -clave en la teoría psicoanalítica de cine de los 60 y 70 - para llevarlo a sus últimas consecuencias, no habríamos que concluir tan rápido que "interfaz" es concepto žižekiano, sino las consecuencias en la composición cinematográfica de la sutura psicoanalítica.

54 S. Žižek, Mirando al Sesgo. Una introducción a Jacques Lacan a través de la cultura popular, Buenos Aires, Paidós, 2002.
La tercera operación es la inversión con vectorización. Por ejemplo, Zupančič 55 nos muestra una estructura que contiene una distancia entre lo que se pide y lo que se obtiene -que es la estructura básica del deseo y la demanda en Lacan- definiendo con ello de manera estructural la comedia (se obtiene algo que jamás se pidió desde el lado de lo que se obtiene) y también de la tragedia (se obtiene algo que no se pidió desde el lado de lo que se demanda). La comedia y la tragedia son los dos lados de una brecha. Se trata entonces de una estructura de brecha insalvable entre lo que se pide y lo que se obtiene. Pero la diferencia entre la comedia y la tragedia es la inversión mediante una vectorización que va de lo que se pide a lo que se obtiene para luego invertirse el vector que va de lo que se obtiene a lo que se pide. El paso de la comedia a la tragedia implica una estructura -que aparece por medio de la repetición- donde el vector se invierte. La estructura y sus vectores se mostrarían así:

$$
\begin{aligned}
& \text { Lo que se pide } \rightarrow \text { Lo que se obtiene } \\
& \text { (la brecha vista trágicamente) } \\
& \text { Lo que se pide } \leftarrow \text { Lo que se obtiene }
\end{aligned}
$$$$
\text { (la brecha vista cómicamente) }
$$

O dicho de otra manera:

$$
\begin{aligned}
& \text { No obtuve algo que esperaba (Tragedia) } \\
& \text { Obtuve algo que no esperaba (Comedia) }
\end{aligned}
$$

La última operación a desarrollar es la de redoblamiento: redoblar una negatividad con otra negatividad. Se trata de una superposición de dos agujeros, o de dos faltas, o de dos impasses. Esta operación se encuentra ya en la concepción del objeto amboceptor en Lacan. Este objeto, luego llamado objeto $a$ en el Seminario 11, se expresa a través de la intersección de dos faltas en un diagrama de Venn: aquello que descompleta al Otro pero también al sujeto. Podemos encontrar esta operación de redoblamiento en la estructura y la dinámica de la comedia, de nuevo, según Alenka Zupančič ${ }^{56}$. La comedia no es definida como un género sino como una estructura de dos cadenas significantes, donde un significante amo que zigzaguea entre una cadena y otra produce un plus de goce, el cual a su vez se adhiere al significante amo zigzagueante. Ésta es su dinámica. Ahora bien, el objeto $a$ que se anuda al significante amo no es otra cosa que la conjunción de dos malentendidos: lo que no tiene sentido en cada una de las dos cadenas significantes se redobla y estabiliza la dinámica.

Es así como una negatividad al redoblarse se positiviza reteniendo la negatividad. Es entonces posible $h a-$ cer algo con el impasse (malentendido, negatividad), y no únicamente mostrar y regodearse en el impasse mismo. Lo anterior es equivalente al paso lacaniano de la impotencia a la imposibilidad, siendo la impotencia el regodeo del impasse y la imposibilidad el motor para poder hacer algo con el impasse. Otros ejemplos son el amor como el redoblamiento de dos fracasos de la rela-

\footnotetext{
5 A. Zupančič, Sobre la comedia: un extraño en casa, México, Paradiso, 2012.

56 A. Zupančič, op. cit., cf. especialmente el capítulo "Dinámica estructural y temporalidad de la comedia".
} 
ción sexual (en términos lacanianos) o las comedias de identidad equivocada $u$ óperas de identidad fingida, muy utilizadas por la Escuela eslovena para explicar cómo una mentira redoblada por otra mentira tiene como efecto una verdad. Mediante esta misma operación Žižek explica justamente el éxito de $S O I^{57}$, como un redoblamiento del fracaso conduce al éxito:

La pregunta es ¿qué lugar tiene hoy el psicoanálisis? [...] El sublime objeto de la ideología trata de responder a esta pregunta rehabilitando en el psicoanálisis su núcleo filosófico - como una teoría que le debe mucho a la dialéctica de Hegel y que únicamente puede ser leída con ese trasfondo-. Esto parece, quizás, el peor movimiento que se puede hacer: tratar de salvar al psicoanálisis, una teoría (y una práctica) desacreditada, haciendo referencia a una teoría todavía más desacreditada, la peor forma de filosofía especulativa que ha sido señalada como irrelevante por el progreso de la ciencia moderna.

Sin embargo, tal como nos enseña Lacan, cuando nos confrontamos con una decisión aparentemente muy clara, a veces lo mejor que uno puede hacer es elegir la peor opción. Mi apuesta fue (y sigue siendo) que, a través de su interacción (leyendo a Hegel a través de Lacan y viceversa), el psicoanálisis y la dialéctica hegeliana sean simultáneamente redimidas entre sí, abandonando sus viejos hábitos y emergiendo en una nueva e inesperada forma.

Señalábamos al introducir las operaciones que estas permiten una lectura sintomática de una situación, un concepto, un caso. Positivizar esta negatividad es lo que posibilita un hacer algo con la negatividad. En ello radica su diferencia con la deconstrucción, por ejemplo. No se trataría únicamente de localizar el callejón sin salida, el atolladero o "la imposibilidad que hace posible" - para expresarlo a la manera de Derrida- en una frase, texto o teoría, sino de hacer algo con ello. En efecto, el punto en común entre Hegel y Lacan, o donde se potenciarían, está en su fuerza para concebir la negatividad.

El buen hegeliano sabe contar más de tres significaría que en la Aufhebung no estarían únicamente retenidas y superadas la afirmación y la negación, sino que siempre quedaría un resto indivisible (indivisible reminder) de la noche del mundo especulada tanto por Schelling como por Hegel. En este sentido Una voz y nada á $^{58}$ es instructivo: Dolar realiza distintos recorridos (históricos, disciplinares o de la vida cotidiana) para encontrar siempre un resto inasimilable de la voz en el acento de los idiomas, en el hipo, en la voz de la consciencia, en los esfuerzos por hacer notaciones fonéticas en la lingüística o en el intento de imitar la voz en los robots y computadoras. En resumen, la Escuela eslovena encontraría en un detalle la posibilidad de leer de otra manera todo el texto. Este detalle implicaría la mayoría de las veces un impasse, un callejón sin salida, una paradoja lógica, una inconsistencia. Estos impasses o paradojas implican distintos tipos de negatividad,

\footnotetext{
57 S. Žižek, "Preface to the New Edition: The Idea's Constipation?", en The Sublime Object of Ideology, Londres, Verso, 2008, p. x (traducción de los autores).
}

58 M. Dolar, Una voz y nada más, Buenos Aires, Manantial, 2007. estas negatividades pueden positivizarse sin perder la potencia de su negatividad y no se quedarían en la imposibilidad o el impasse. Es posible hacer algo con el vacío, el agujero, la hiancia, el impasse, la división, la negatividad: en eso consistirían las lecciones lacanianas y hegelianas ${ }^{59}$.

Nosotros sostenemos que esta lectura es imposible sin el psicoanálisis lacaniano. ¿Por qué? ¿Qué hay de novedad en el psicoanálisis de Lacan? El psicoanálisis lacaniano es una práctica de la interpretación en los límites del sentido, es decir la interpretación que apunta a tratar con lo real. La introducción de lo real en los límites y confines de lo simbólico es algo que nunca dejó de pensar y practicar Jacques Lacan ${ }^{60}$. Diga lo que se diga de Žižek y de la Escuela eslovena, ellos practican el psicoanálisis ${ }^{61}$. Lacan, por ejemplo, no se preguntaba tanto si el psicoa-

59 La resonancia de estas palabras -vacío, agujero, negatividad, división, etc.- están en los temas y títulos de varios libros, artículos y conferencias. Cf. A. Cerda-Rueda (ed.), Sex and Nothing: Bridges from Psychoanalysis to Philosophy, Londres, Karnac, 2016 (con artículos de tres autores latinoamericanos: Pavón-Cuéllar, Cerda-Rueda y Soto van der Plas). Otros artículos y libros abordan explícitamente la cuestión del vacío, la nada y la negatividad: M. Dolar, "Tyche, Clinamen, Den", en revista Continental Philosophy Review, vol. 46, no. 2, Agosto 2013, pp. 223-239; M. Dolar, "One divides into Two", en revista e-flux, no. 33, marzo 2012, pp. 1-12; M. Dolar, "Hegel and Freud", en revista e-flux, no. 34, octubre 2012, pp. 1-12 (el cual es una transcripción de una conferencia de igual título, pero con un subtítulo: la negatividad y sus vicisitudes); A. Zupančič, "Sexual Difference and Ontology", en revista e-flux, no. 32, febrero 2012, pp. 1-12; A. Zupančič, "Sex, Ontology, Subjectivity: In conversation with Alenka Zupančič", en revista Psychoanalysis, Culture \& Society, vol. 20, no. 2, 2015, pp. 192-206; S. Žižek, La permanencia de lo negativo, Buenos Aires, Godot, 2016; S. Žižek, Menos que nada. Hegel y la sombra del materialismo dialéctico, Madrid, Akal, 2015. Los capítulos “¿Ser o no ser? No, gracias” de M. Dolar y "La sexualidad en los límites de la mera razón" de A. Zupančič también ilustran perfectamente este interés por la negatividad y el vacío. De paso diremos que el exitoso evento de la troika en ICI Berlin un año antes de su visita a México se titula nada menos que "Uno se divide en Dos: dialéctica, negatividad, clinamen". La recopilación y la traducción de varios artículos del inglés y del esloveno al español de Mladen Dolar fueron justamente titulados "Uno se divide en dos" y hablan sobre la dialéctica, la negatividad y también el clinamen. Cf. M. Dolar, Uno se divide en dos. Más allá de la interpelación, Ciudad de México, Paradiso, 2013. La visita a México de la troika fue organizada por Alejandro Cerda Rueda y Carlos Gómez Camarena, visita que tuvo lugar en la Universidad Iberoamericana y el Cine Tonalá en la Colonia Roma.

60 La praxis del psicoanálisis supone siempre "la posibilidad de tratar lo real mediante lo simbólico" J. Lacan, El seminario. Libro XI. Los cuatro conceptos fundamentales del psicoanálisis, Buenos Aires, Paidós, 2003, p. 14.

61 No se trataría de una práctica clínica, principalmente por cuestión de la transferencia, el hacerse cargo de la angustia, la importancia de la respuesta del analizante, etc. Pero es una práctica del psicoanálisis. "Hay que saber que en el filósofo siempre suele darse una suerte de rechazo de la transferencia y tal vez Žižek no sea en esto una excepción, pero no se le puede pedir a cada filósofo o político que se interese por Lacan y que también se vuelva psicoanalista. Esto sería empobrecer el alcance especial que la enseñanza de Lacan va teniendo en el siglo XXI", J. Alemán, Lacan, la política en cuestión... Conversaciones, notas y textos, Buenos Aires, Grama, 2010, p. 103. Alenka Zupančič afirma que en la actualidad tanto el psicoanálisis como la filosofía han ganado mucho al exponer sus conceptos al otro campo de saber, discute incluso el affaire de la excomunión de Lacan por su excesiva "intelectualización", mencionando que justo el escándalo para la International Psychoanalytical Association es que el inconsciente se comporta de manera sumamente racional, justo a la manera de las matemáticas, la literatura o la filosofía. Cf. A. Zupančič, What is Sex, Massachusetts, MIT University Press, 2017, p. 3. 
nálisis era científico sino qué sería una ciencia que incluyera al psicoanálisis ${ }^{62}$. Diremos entonces que el programa filosófico de la Escuela eslovena es tomarse en serio al psicoanálisis - como práctica de interpretación en los confines del sentido- e incluirlo en las más diversas disciplinas y campos de saber. ¿Qué es una filosofía que incluya al psicoanálisis?, ¿qué son los cultural studies cuando incluyen al psicoanálisis?, ¿qué es un arte que incluye al psicoanálisis?, ¿qué hay de una teología que incluya al psicoanálisis? En suma, la originalidad de la Escuela eslovena -y en último término de El sublime objeto de la ideología - es el de hacer una lectura lacaniana que es suplementada por Hegel. Es una lectura sintomática, llena de negatividad e impasses, que pone a prueba al texto en los confines del sentido para elucidar lo real -goce, fantasma, hiancia, pulsión, resto. Esta lectura es efecto de operaciones, tal como las definimos anteriormente.

Esta estructura que aparece mediante la repetición es una clave de lectura también para leer a Žižek: en el frenético cambio de temas y ejemplos en la escritura del esloveno, se repite una estructura que encuentra un mismo impasse, que invierte una vectorización o que al repetir hay pequeñas diferencias o desplazamientos. Es por esta misma razón que lo que mencionamos anteriormente como un rasgo - pasar de un tema a otro, hablar de la cultura pop- se parece en su fenomenología al "marxismo MTV"63, a un montaje de videoclip. Pero se trata más bien de figuras aparentemente disímiles donde se despliega una estructura y donde se pueden discernir las operaciones que hemos mencionado.

Es posible que el lector pueda localizar más operaciones. Este artículo daría los elementos mínimos para poder identificarlas. Nuestro argumento final es que estas operaciones producen efectos en lo real que no pueden reducirse al sentido ni abordarse mediante la interpretación.

\subsection{Lecturas}

Una vez señalados los rasgos de estilo y las operaciones que a través de estos rasgos crean nuevas relaciones conceptuales, se permite entrever lecturas de la Escuela eslovena, es decir, operaciones que a gran escala se distinguen en su proyecto filosófico. Mientras que las operaciones del anterior apartado estaban circunscritas

62 "Entonces, la pregunta que constituye nuestro proyecto radical seguía siendo permanente, la que va de: ¿el psicoanálisis es una ciencia? a: ¿qué es una ciencia que incluya al psicoanálisis?”, J. Lacan, "Los cuatro conceptos fundamentales del psicoanálisis. Reseña del seminario de 1964", en Otros escritos, Buenos Aires, Paidós, 2012, p. 205.

63 "Marxismo MTV" es el nombre que le da Clint Burnham a un marxismo trendy y a la moda que abarca tanto a la cultura pop como escritos teóricos. "No recuerdo no haber no leído a Jameson" es la expresión que utiliza para referirse a uno des sus filósofos marxistas favoritos. Burnham continúa "yo sostengo que muchos intelectuales de mi generación leyeron a Jameson como si fuera cultura pop (...) Jameson está en el mismo plano que Shabba Ranks y PJ Harvey, pero también entre Deep Nine y John Wo: significantes culturales en los cuales uno podría ser igualmente «fan» como «crítico»", C. Burnham, The Jamesonian Unconscious: The Aesthetics of Marxist Theory, Durham, Duke University Press, 1995, p. 244. Este "Marxismo MTV" ha sido asociado no sólo a Frederic Jameson sino a Žižek y a Terry Eagleton también. para problematizar algún caso o algún concepto muy específico, las lecturas son operaciones que se tejen a lo largo de todo un texto, y que por ello son transversales en la obra académica de la Escuela eslovena. Por ello, van al final: sólo es posible entender estas lecturas gracias a las operaciones antes señaladas. Identificamos, entonces, tres de ellas: 1) la lectura hegeliana de la identidad, donde la identidad es posible por la imposibilidad de ser idéntico a sí mismo, 2) el intento de trabajar con un resto inasimilable como impasse conceptual, y 3) el mirar torcido, donde la intromisión de una mirada supone la nueva lectura de toda la situación.

Para la Escuela eslovena, la idea más importante del idealismo alemán es que la verdad es algo que se encuentra siempre fuera de sí misma, dislocada ${ }^{64}$. Esto se manifestaría, entre otras cosas, como la imposibilidad de cualquier identidad. La identidad de algo, su singularidad o "unidad" sería siempre una división, un corte o una no-coincidencia consigo misma. En otras palabras, siempre hay un demasiado, un "remanente indivisible" que no permite a ese algo, ser idéntico a sí mismo. Esto compone la lectura hegeliana de la identidad. Esta noidentidad, este origen no-idéntico atraviesa casi cualquier concepto: el yo, el sujeto, Dios o hasta la ontología. Para la Escuela eslovena es importante problematizar los conceptos leyéndolos en principio como fuera de sí o con una identidad escindida en el origen.

Por ejemplo, de acuerdo a la Escuela eslovena, la teoría lacaniana del estadio del espejo muestra significativas similitudes de fondo con la filosofía fichteana del yo ${ }^{65}$. Fichte sería el "filósofo del puro yo", que problematizaría su unidad. Pero no únicamente eso, sino que Fichte sería el primer filósofo que propondría a la contingencia como el corazón de la subjetividad y que esto estaría relacionado con el Ansto $\beta$, es decir, con un obstáculo interno al propio yo -aquí reside la cuestión una verdad que está fuera de sí misma-. Este obstáculo sería homólogo al objeto $a$ lacaniano.

Del mismo modo, en esta lectura se plantea que fue Schelling quien habría formulado por vez primera la cuestión lacaniana de un corte como condición necesaria para ingresar en el orden simbólico ${ }^{66}$, pero también quien concibe la prehistoria de dios como un antagonismo interno, "un Dios que todavía no es Dios"67, un Schelling que muestra "el antagonismo de la prehistoria de Dios, resuelto cuando Este pronuncia Su Palabra" ${ }^{\text {. }}$. Todo esto, alegarán los miembros de la Escuela eslovena, son lecturas que no han sido reconocidas todavía en la filosofía ${ }^{69}$. Es por eso que en Schelling, a nivel de la creación divina - $\mathrm{O}$ el origen de todas las cosas-, estaría

64 R. Riha, Kant in Lacan'scher Absicht. Die kopernikanische wende und das Reale, Viena, Turia+Kant, 2018.

65 S. Žižek, "Fichte's Laughter", en M. Gabriel y S. Žižek, Mythology, Madness, and Laughter. Subjectivity in German Idealism, Londres, Continuum, 2009, pp. 122-167.

${ }_{66}$ S. Žižek, Las metástasis del goce. Seis ensayos sobre la mujer y la causalidad, Buenos Aires, Paidós, 2003, p. 198.

67 Idem.

68 S. Žižek, ;Goza tu síntoma! Jacques Lacan dentro y fuera de Hollywood, Buenos Aires, Nueva Visión, 1994, p. 69.

69 M. Dolar, "Hegel or Spinoza? Yes, Please!", en G. Moder, Hegel or Spinoza. Substance and Negativity. Evanston, Northwestern University Press, 2017, pp. ix-xii. 
también marcado por una imposibilidad de identidad, de coincidencia consigo mismo. El Inicio o el Comienzo de todo residiría en una fractura interna a la identidad ${ }^{70}$.

Pero también para la Escuela eslovena el psicoanálisis lacaniano es dialéctico en el sentido hegeliano y por ello sobrepasa el campo del estructuralismo. Se trataría de una radicalización del racionalismo del Siglo de las Luces $^{71}$.

Por esa razón, antes que Fichte o Schelling, el sujeto lacaniano tendría una larga tradición que habría comenzado con la filosofía de Kant. Un sujeto que está dividido y además descentrado entre el sujeto del enunciado y de la enunciación. Esto no estaría dicho así por Kant, pero se puede leer a través de la división y descentramiento entre el sujeto trascendental y el sujeto empírico ${ }^{72}$.

Esta lectura hegeliana -o idealista alemana- radicalizada por el Lacan de la Escuela eslovena nos permite, por ejemplo, ir más allá del noúmeno-fenómeno de Kant a través del par semblante-estructura de Lacan. En efecto, mientras que el noúmeno sólo puede manifestarse en un fenómeno, es decir, todos los fenómenos son una manifestación posible para la experiencia sensible del noúmeno al que indican -algo parecido al ejemplo idealista, señalado en los rasgos-; por su parte la estructura no es esta idea suprasensible que el semblante atisba a representar, sino que el semblante es la estructura misma, y por ello nos otorga las pistas de lo que falla en la estructura: toda estructura tiene una falla constitutiva, y la prueba de ello es la imposibilidad de ser representada en el semblante -lo que lo acercaría la ejemplo materialista-. En otras palabras: en la dicotomía kantiana, la falla está del lado del fenómeno por no ser capaz de representar en su totalidad la noúmeno, lo que le entregaría dignidad a este último al estar en completud; en la dicotomía lacaniana, la falla está, al contrario, del lado de la estructura, pues esa falla es la que posibilita que la estructura misma exista, y la

Es crucial esta lectura hegeliana de Lacan o lectura lacaniana de Hegel para poder entender el concepto de real en la Escuela eslovena. Lo real no es algo inefable, sino como lo menciona Lacan "lo real no puede inscribirse sino como un impasse en la formalización" ( $\mathrm{J}$. Lacan, El seminario. Libro XX. Aun, Buenos Aires, Paidós, 2008). En otras palabras, lo real es el propio impasse -la no-coincidencia, la no identidad- de una noción o concepto. Esto no es únicamente importantísimo para poder entender la relación entre Hegel y lo real en la Escuela eslovena, sino también para poder comprender que los ejemplos aparentemente disímiles muestran que en el fondo tienen una misma estructura, pero que esta estructura a su vez se sostiene por una falla, por un impasse. La estructura es la formalización, el impasse es lo real. Por esta misma razón hay una relación íntima entre la cultura pop y el matema como transmisión en el psicoanálisis lacaniano. Recordemos que el matema es justamente un impasse en la formalización. ¿Pero qué transmite un matema? Un impasse, un corto cirtuito o en términos hegelianos una no-identidad. Los chistes, las anécdotas o las escenas de cine -todas ellas extraidas de la cultura pop- transmiten un impasse en nuestra cultura. Es por eso que la Escuela eslovena usa esos ejemplos también para transmitir. No sería casualidad que el "café sin leche" (que es distinto de un “café sin azúcar") sea tan eficaz para transmitir algo tan complicado como lo real, es decir, un impasse. La Escuela eslovena elevó ciertos fragmentos de la cultura pop al estatuto de matema.

71 S. Žižek, El sublime objeto de la ideología, México, Siglo XXI, 1992, p. 30.

72 S. Žižek, Las metástasis del goce. Seis ensayos sobre la mujer y la causalidad, Buenos Aires, Paidós, 2003, p. 275. prueba de esa falla es la incapacidad del semblante de representar la estructura misma ${ }^{73}$.

Para comprender esto, Žižek nos indica ${ }^{74}$ un nuevo modo de comprender el rol del rey. ¿Por qué Hegel propone la figura del monarca para el funcionamiento del Estado? ¿No se da cuenta acaso del carácter contingente $\mathrm{y}$ arbitrario de que el jefe de Estado se decida por simplemente ser el hijo del actual jefe? Precisamente por esa razón, pues así la monarquía adquiere un carácter puramente formal y simbólico, suelto a una cuestión tan irracional como el linaje sanguíneo puede entonces conformarse una comunidad racional a su alrededor. Así, la persona que ocupe el puesto siempre estará ajena al puesto mismo: una brecha irreductible separará el semblante (la persona física específica) de la estructura (el puesto de "monarca"), pues la estructura misma es una irracionalidad simbólica. A esto se refiere entonces el aforismo hegeliano - tan usado por la Escuela eslovena"El Espíritu es un hueso": no existe el Espíritu habitando en los cielos o un universo paralelo, en lugar de ello debemos conformarnos con el hueso de carne perecedera y finita; o como bien señalaba Luis XIV, el monarca es el Estado: el Estado no existe sino en su presencia. No es que él sea el digno semblante que representa la estructura: él es la estructura, en tanto ocupa el lugar específico en la red simbólica para ser el Estado.

Este ejemplo del monarca es una lectura de la Escuela eslovena de la filosofía política de Hegel, pero podemos hallar sus consecuencias para el campo psicoanalítico: las fórmulas de la sexuación corresponden justo con ello. El ser hablante que es mujer u hombre no lo es por poseer ciertas características biológicas (esto pondría al psicoanálisis en el saco de las ciencias médicas), ni por poseer ciertas características socio-históricas o políticamente definidas (esto pondría al psicoanálisis en el saco de los estudios de género, la sociología de género o la psicologización del sexo). Uno es hombre porque es su modo de expresar el impasse estructural de su propia constitución subjetiva, y por ello una posición sexuada se define en contraposición a la otra. Una mujer es mujer porque no es hombre, un hombre es hombre porque no es mujer: adoptar la idea de que "un hombre es X características" sería suponer una identidad de "El Hombre", o de "La Mujer", a dos pasos de la peligrosa lógica de poder decir quién es más o menos hombre o mujer ${ }^{75}$.

En este sentido, en la lectura hegeliana-lacaniana del idealismo alemán cada filósofo de esta época problematizaría la identidad, mostraría su división y la radicalizaría. $\mathrm{Su}$ culmen sería Lacan, quien revelaría en retrospectiva todo este movimiento. Es así que Hegel inauguraría la modernidad filosófica al inscribir la escisión y la nocoincidencia en el origen ${ }^{76}$.

\footnotetext{
Para profundizar en el par semblante-estructura, ver J. Šumič, "On the Path of Semblant", en Umbr(a) 1, 2007.

74 S. Žižek, Porque no saben lo que hacen, Buenos Aires, Paidós, 1998, p. 116.

75 Para un desarrollo de esta lectura hegeliana-lacaniana pero desde las antinomias de la razón de Kant, cf. J. Copjec, El sexo y la eutanasia de la razón, Buenos Aires, Paidós, 2006. Joan Copjec ha fungido desde hace años como una especie de satélite de la Escuela eslovena, al igual que Robert Pfaller o Eric Santner.

76 En este sentido, vale la pena citar extensamente la manera en que Badiou lee esta modernidad filosófica en Žižek (pero nosotros lo ha-
} 
El intento de trabajar con un resto inasimilable, segunda de las lecturas de la Escuela eslovena, es un gesto de localizar el impasse de una conceptualización. Es un gesto de lectura cercano a la idea de Jacques Rancière de "la parte sin parte" las causas perdidas ${ }^{78}$, Žižek se pregunta cuál podría ser la nueva clase que ocuparía el lugar estratégico para la revolución que ocupaba el proletariado. Localiza a ésta en el producto del capitalismo de explotación: las zonas marginales de las grandes ciudades, que viven en la zona limítrofe de las megalópolis y del control del estado, ajenos a cualquier integración en lo que sea que quede del estado de bienestar pero aún así participantes de la economía, ya sea como emprendedores mismos en las zonas oscuras (piratería, negocios ilegales). Este resto inasimilable, que no es proletariado pero no es campesino, es producto de la explotación capitalista y a la vez su renegación: nos recuerda su presencia que el capitalismo es un circuito que no sólo produce bienes y servicios, sino también desechos: los desechos industriales de basureros tecnológicos, y los desechos humanos que, de manera literal en muchos casos, viven entre esos basureros ${ }^{79}$. Su existencia vuelve necesaria la re-actualización de Marx y su conceptualización de la clase obrera, pero no en un sentido positivista ingenuo ("la realidad actual ha superado las ideas marxistas"), sino de volver a enfrentar la lectura más "evidente" de la realidad con el fantasma del marxismo. Este resto inasimilable es trabajado por toda la Escuela eslovena. Como

cemos extensivo a toda la Escuela eslovena): "De cierta manera, la consistencia de las leyes que estructuran al conocimiento, que estructuran al sujeto transcendental, hacen que incluso si yo no me puedo representar algo, la operación representante como tal persiste en ser en tanto que es menos que nada. Es así que inicia con el nacimiento del idealismo alemán la captación de lo real como falla interna, disidencia inmanente, desfase no resuelto, esto es, en general todas las formas vivas de la negación. (...) El entendimiento de las razones por las cuales Hegel puede sostener que el absoluto es particularmente activo en el decir de quien contradice su existencia proviene de la misma insistencia lógica. El mejor síntoma del ser radica en la diferencia casi nula entre su decir y su dicho o entre su acto y el mero hecho de proferirlo. De donde surge una representación de la historia mundial de la filosofía. El idealismo alemán inaugura una historia de la filosofía, historia que puede declinarse según Slavoj Žižek en 6 etapas. En primer lugar la prehistoria griega, importante pero prehistórica. En segundo lugar, un nacimiento crítico, con Kant. Posteriormente, dos insistencias idealistas: Fichte y Schelling. En cuarto lugar, una matriz dialéctica definitiva, entrecomillado, en Hegel. En un quinto momento, una repetición creadora en Lacan de Hegel. Y en sexto lugar, una repetición creadora de la repetición creadora de Hegel por Lacan, a saber, Žižek", A. Badiou "La méthode de Slavoj Žižek" prefacio a la edición francesa de S. Žižek, Moins que rien. Hegel et l'ombre du matérialisme dialectique, París, Fayard, 2015, pp. 16-17.

77 J. Rancière, El desacuerdo. Filosofía y Política, Buenos Aires, Nueva Visión, 1996.

78 S. Žižek, En defensa de las causas perdidas, Madrid, Akal, 2008, pp. 434-437.

79 En este sentido, una de las novedades de la Escuela eslovena es concebir la ideología de una manera no representacional o explicándola como algo falso que se opone a la realidad. La ideología entonces ya no es algo que encubre la realidad sino que pretende negar, encubrir o ignorar lo real. La ideología es la respuesta a quienes no quieren saber nada de la inconsistencia o incompletud, sea de la sociedad, de un sistema económico o de las leyes de un país. En este sentido, tratar de deshacerse de un resto inasimilable -el proletario, el inmigrante, el judío- es esencialmente ideológico, pues es el procedimiento clave para dar cuenta de un relato del mundo donde "eso marche". inestabilidad en la ciencia en el caso de Samo Tomšič, como una materialidad espectral en Alenka Zupančič o la voz como objeto $a$ en Mladen Dolar ${ }^{80}$. Pero también este resto inasimilable es la manera en que Žižek distinguirá la crítica ideológica tradicional ("desenmascarar la ideología para mostrar las cosas como realmente son", lo que incluiría, para el nazismo, creer que el judío es la causa de la tragedia alemana) de la crítica ideológica después de Lacan (no se trata de desenmascarar nada sino de entender cómo se crea un enmascaramiento para ocultar otro: culpar al judío es usarlo como chivo expiatorio de los antagonismos del sistema capitalista ${ }^{81}$ ).

Finalmente, esta lectura de la identidad a través de Hegel y la introducción de un resto inasimilable nos propone la tercera lectura esencial del proyecto filosófico de la Escuela eslovena: la capacidad de mirar torcido ${ }^{82}$. Al estar la torcedura del lado de la mirada, lo que sucede es una doble reflexividad. Como señala Žižek en el capítulo dedicado a la pornografía y la nostalgia, cuando nos sentimos invadidos por un sentimiento de nostalgia que no "deberíamos" de tener (como cuando sentimos nostalgia, un sentimiento dedicado a hechos pasados, por acontecimientos que nunca sucedieron, o que no presenciamos) lo que sentimos no es una nostalgia por los hechos mismos, sino por estar en la posición del que siente nostalgia. Es decir, actuamos como si sintiésemos nostalgia pues no podríamos sentirla directamente. Una cuestión parecida es la relación que sostiene la pornografía con el punto de vista cinematográfico: jugamos el papel de ser el que está involucrado en el acto, por ello es cada vez más común la pornografía gonzo, que usa a la cámara como el punto de vista del actor que tiene sexo en la escena.

La distinción entre la lectura de mirar torcido y la operación de intromisión, es que en la operación se introduce un elemento extraño que resignifica el cuadro o la escena; mientras que en la lectura es la que establece las condiciones que posibilitan la escena misma. Es decir, en la intromisión hay un Real que se introduce en nuestra configuración simbólica, revelando su contingencia. Al mirar torcido, más bien creamos una Otredad tercera en la que desplazamos la nostalgia, excitación, euforia o miedo que una escena provee. Mientras que la

S. Tomšič, The Labour of Enjoyment. Towards a Critique of Libidinal Economy, Berlín, August 2019; A. Zupančič, Sobre la comedia: un extraño en casa, México, Paradiso, 2012; así como M. Dolar, Una voz y nada más, Buenos Aires, Manantial, 2007.

81 Este ejemplo del nazismo es fundamental para entender la tan criticada, por sacada de contexto, idea zizekiana de que Hitler no fue suficientemente violento: no lo fue pues sus arrebatos ultraviolentos eran un modo desesperado de evitar algo que verdaderamente cambiaría las relaciones existentes: Hitler es la reacción de la ultraderecha ante el avance del comunismo. Cf. S. Žižek, Violence, Nueva York, Picador, 2008.

82 Como notará el lector, esta operación lleva por nombre algo similar al famoso libro de Žižek Mirando al sesgo, Buenos Aires, Paidós, 2002. Sin embargo, es importante anotar que el título original del libro es Looking Awry (publicado originalmente en 1991, Massachusetts, MIT Press), cuya traducción más adecuada sería "Mirando torcido". La diferencia entre "mirar al sesgo" y "mirar torcido" es que en el primer caso la torcedura está en el objeto que se mira (se mira hacia el sesgo), mientras que en el segundo caso la torcedura está en la mirada misma (mirando torcido). Esto es precisamente lo que Žižek señala en el ejemplo que aquí damos. Tomando en cuenta esto, se decidió dejar "mirar torcido" como el nombre de la operación. 
intromisión desestabiliza al Otro, el mirar torcido crea un Otro artificial que nos posibilita una nueva interpretación de una situación. Este mirar torcido es tomado por Žižek del concepto de anamorfosis que Lacan usa para leer el cuadro de Los embajadores de Holbein ${ }^{83}$.

\section{Conclusión}

Lo que hemos querido es mostrar a través del postulado hay una Eslovena es que en lugar de conceptos, existen rasgos, operaciones y lecturas en común que hacen legible su filosofía. De la misma manera, quisimos también mostrar que es leyendo a un miembro de la Escuela eslovena con otro miembro de ella que se hace más comprensible al primero, pero también revela que están en juego ciertos rasgos, operaciones y lecturas. Afirmamos que la esta Escuela tiene un pensamiento que no es individual, que no se trata del ideológico sintagma "trabajo en equipo", sino del vaciamiento del individuo en beneficio del pensamiento impersonal y colectivo que desemboca en trayectos individuales que vienen al lugar donde el Otro falla y nada puede garantizar. Ni individuo heroico -Slavoj Žižek sin su troika-, ni "humildad" del trabajo en equipo, ni colectividad unificada. Este sentido es crucial su lectura hegeliana-lacaniana donde toda la historia de la filosofía puede leerse desde un principio de identidad que está fuera de sí o dislocado. Por último, debido a esta inconsistencia y falla del Otro, la emergencia de la Escuela eslovena no podría explicarse únicamente mediante su contexto histórico o las condiciones sociales y económicas concretas. Tampoco por su influencia intelectual. En esto coincidiría en último término el marcado antihistoricismo foucaultiano y la apuesta por la historicidad acontecimiental badiouana de la Escuela eslovena. Sin el deseo contingente del sujeto esloveno, sin su deseo del Hegel de la división y del absoluto tachado, no serían suficientes ni todos los contextos ni todas las condiciones históricas. Después de todo ¿cómo explicar el éxito y la importancia mundial de esta Escuela en un país sin tradición psicoanalítica y con tan sólo 2 millones de habitantes?

\section{Bibliografía}

Alemán, J., Lacan, la política en cuestión... Conversaciones, notas y textos, Buenos Aires, Grama, 2010.

-, Conjeturas sobre una izquierda lacaniana, Buenos Aires, Grama, 2013.

Badiou, A., Lógicas de los mundos. El ser y el acontecimiento 2, Buenos Aires, Manantial, 2008.

-, "La méthode de Slavoj Žižek" prefacio a la edición francesa de S. Žižek, Moins que rien. Hegel et l'ombre du matérialisme dialectique, París, Fayard, 2015.

Bosteels, B., "Prólogo" en Badiou, A., El cine como acontecimiento, México, Paradiso/Universidad Iberoamericana, 2016.

Burnham, C., The Jamesonian Unconscious the Aesthetics of Marxist Theory, Durham, Duke University Press, 1995.

Butler R., (ed.), The Žižek Dictionary, Londres, Routledge, 2014.

Castro-Gómez, S., Revoluciones sin sujeto. Slavoj Žižek y la critica del historicismo posmoderno, México, Akal, 2015.

Cerda-Rueda, A., (ed.), Sex and Nothing: Bridges from Psychoanalysis to Philosophy, Londres, Karnac, 2016.

Chion, M., La voz en el cine, Madrid, Cátedra, 2004.

Copjec, J., El sexo y la eutanasia de la razón, Buenos Aires, Paidós, 2006.

Cusset, F., French Theory, Tenerife, Melusina, 2005.

Dolar, M., Una voz y nada más, Buenos Aires, Manantial, 2007.

-, "One divides into Two", en revista e-flux, no. 33, marzo 2012, pp. 1-12.

-, "Hegel and Freud", en revista e-flux, no. 34, octubre 2012, pp. 1-12.

-, “Tyche, Clinamen, Den”, en revista Continental Philosophy Review, vol. 46, no. 2, Agosto 2013, pp. $223-239$.

-, Uno se divide en dos. Más allá de la interpelación, México, Paradiso, 2013.

-, "Hegel or Spinoza? Yes, Please!", en G. Moder, Hegel or Spinoza. Substance and Negativity, Evanston, Northwestern University Press, 2017

Guerrero, L. y Cavallazzi, A., La filosofia del siglo XX: un mapa bibliográfico, México, Universidad Iberoamericana, 2010.

Irwin, J. y Motoh, H., Žižek and his Contemporaries. On the Emergence of the Slovenian School, Londres, Bloomsbury, 2013.

Jameson, F., "The Vanishing Mediator; or, Max Weber as Storyteller”, en New German Critique 1, 1973, pp. 52-89.

Johnston, A., Žižek's Ontology: A Trascendental Materialist Theory of Subectivity, Illinois, Northwestern University Press, 2008.

Kay, S., Žižek: A Critical Introduction, Cambridge, Polity, 2003.

Kotsko, A., Žižek and Theology, Londres, T\&T Clark, 2008.

McGowan, T., "Introduction: Enjoying the Cinema", en International Journal of Žižekian Studies, Vol. 1, 3(2007).

Myers, T., Slavoj Žižek, Routledge, Londres, 2003.

Monroe, A., Interrogation Machine: Laibach and NSK. MIT Press, Cambridge, 2005.

Lacan, J., El seminario. Libro XI. Los cuatro conceptos fundamentales del psicoanálisis, Buenos Aires, Paidós, 2003.

-, El seminario. Libro XX. Aun, Buenos Aires, Paidós, 2008.

-, "Los cuatro conceptos fundamentales del psicoanálisis. Reseña del seminario de 1964", en Otros escritos, Buenos Aires, Paidós, 2012.

Parker, I., Slavoj Žižek. A Critical Introduction, Londres, Pluto Press, 2004.

Pond, M., Žižek: A (Very) Critical Introduction, Cambridge, Eerdermans, 2008.

Rancière, J., El desacuerdo. Filosofía y Política, Buenos Aires, Nueva Visión, 1996.

Riha, R., Kant in Lacan'scher Absicht. Die kopernikanische wende und das Reale, Viena, Turia+Kant, 2018.

83 J. Lacan, El seminario. Libro XI. Los cuatro conceptos fundamentales del psicoanálisis, Buenos Aires, Paidós, 2003. 
Sharpe, M. y Boucher, G., Žižek and Politics: A Critical Introduction, Edimburgo, Edinburgh University Press, 2010.

Stavrakakis, Y., La izquierda lacaniana. Psicoanálisis, teoría, política, Buenos Aires, Fondo de Cultura Económica, 2010.

Šumič, J., "On the Path of Semblant", en Umbr(a) 1, 2007.

Taylor, P., Žižek and the Media, Cambridge, Polity, 2010.

Tomšič, S., The Labour of Enjoyment. Towards a Critique of Libidinal Economy, Berlín, August 2019.

Vighi, F., On Žižek's Dialectics. Surplus, Subtraction, Sublimation, Londres, Continuum, 2010.

Wright, E. y Wright, E. (eds.), The Žižek Reader, Oxford, Blackwell, 1999.

Žižek, S., Le plus sublime des hystériques Hegel passe, París, Point hors ligne, 1988.

-, El sublime objeto de la ideología, México, Siglo XXI, 1992.

-, "Ethnic Dance Macabre", en The Guardian Manchester, 28 de agosto de 1992.

-, ;Goza tu síntoma! Jacques Lacan dentro y fuera de Hollywood, Buenos Aires, Nueva visión, 1994.

-, Todo lo que usted siempre quiso saber sobre Lacan y nunca se atrevió a preguntarle a Hitchcock, Buenos Aires, Manantial, 1994.

-, Porque no saben lo que hacen, Buenos Aires, Paidós, 1998.

-, "You May!", London Review of Books 21, No. 6, 1999.

-, "Attempts to Escape the Logic of Capitalism", en London Review of Books, 28 de octubre de 1999.

-, The Fragile Absolute. Why is Christian Legacy Worth Fighting For?, Nueva York, Verso, 2001.

-, Enjoy your symptom! Jacques Lacan in Hollywood In and Out, Nueva York, Routledge, 2001.

-, The Fright of Real Tears. Krzysztof Kieslowski Between Theory and Post-Theory, Londres, British Film Institute, 2001.

-, Mirando al Sesgo. Una introducción a Jacques Lacan a través de la cultura popular, Buenos Aires, Paidós, 2002.

-, Las metástasis del goce. Seis ensayos sobre la mujer y la causalidad, Buenos Aires, Paidós, 2003.

-, Cómo leer a Lacan, Buenos Aires, Paidós, 2008.

-, Jacques Lacan: Critical Evaluations in Cultural Theory, Londres, Routledge, 2003.

-, Violence, Nueva York, Picador, 2008.

-, "'Preface to the New Edition: The Idea's Constipation?", en The Sublime Object of Ideology, Londres, Verso, 2008.

-, En defensa de las causas perdidas, Akal, Madrid, 2011.

-, Less than Nothing. Hegel and the Shadow of Dialectical Materialism, Londres, Verso, 2012.

-, El más sublime de los histéricos, Buenos Aires, Paidós, 2013.

-, Menos que nada. Hegel y la sombra del materialismo dialéctico, Madrid, Akal, 2015.

-, La permanencia de lo negativo, Buenos Aires, Godot, 2016.

-, El espanto de lágrimas reales, México, Paradiso/Universidad Iberoamericana, 2020.

- y Daly, G., Conversations with Žižek, Cambridge, Polity, 2004.

- y Gabriel, M., Mythology, Madness, and Laughter. Subjectivity in German Idealism, Londres, Continuum, 2009.

A. Zupančič, The Shortest Shadow. Nietzsche's Philosophy of the Two, Cambridge, MIT, 2003.

-, Sobre la comedia: un extraño en casa, México, Paradiso, 2012.

-, "Sexual Difference and Ontology”, en revista e-flux, no. 32, febrero 2012, pp. 1-12.

-, "Sex, Ontology, Subjectivity: In conversation with Alenka Zupančič", en revista Psychoanalysis, Culture \& Society, vol. 20, no. 2, 2015, pp. 192-206.

-, What is Sex, Massachusetts, MIT University Press, 2017. 